\title{
Chemical Risk: Criação de um Jogo Didático para o Ensino de Biossegurança
}

Cristina Northfleet de Albuquerque ${ }^{1 *}$; Luiz Fernando de Souza2; GradP Wilker Alves de Moura²; Daniel Martins da Silva Oliveira²; Gledson Kleiton da Silva2; Alvaro Gabriele Rodrigues²

${ }^{1}$ Faculdade de Ciências Farmacêuticas da Universidade de São Paulo

${ }^{2}$ Curso de Design de Games da Fatec Carapicuíba

* Autor para correspondência: northfle@usp.br

\section{RESUMO}

O Chemical Risk é um projeto didático que visa a demonstrar a utilização de jogos na educação por meio do desenvolvimento de um jogo digital, cujo objetivo primeiro é a fixação dos principais conceitos de Biossegurança. Tal proposta promove uma reflexão sobre o modelo de ensino tradicional e propõe um novo conceito que se alia à evolução tecnológica, sugerindo, assim, novas formas de transmissão de conhecimento. A fim de proporcionar aos jogadores uma prática para aprender a respeito dos conceitos de Biossegurança, este projeto trata justamente da familiarização do aluno com tais conceitos, uma vez que irá permitir a simulação de um acidente químico em um ambiente laboratorial, dando ao graduando a possibilidade de aplicar e consolidar os conceitos que aprendeu em sala de aula. Como base bibliográfica, o presente projeto buscou referências em livros acadêmicos, portais on-line e artigos sobre o uso de métodos lúdicos na educação e a aprendizagem mediante jogos de computador.

Palavras-chave: Riscos Químicos; Aprendizagem; Biossegurança; Jogo Digital; Educação.

\begin{abstract}
Chemical Risk is an educational project that aims to demonstrate the use of games in education through the development of a digital game, whose first goal is the establishment of Biosafety's key concepts. This proposal promotes a reflection about the traditional teaching model and proposes a new concept that allies itself to the technologic evolution, thus suggesting new ways of knowledge transmission. In order to provide to the players a practice learning about the biosafety's concepts, this project proposal deals justly with the familiarization of the student with such concepts, since it will permit the simulation of a chemical accident in a laboratorial environment, allowing the student to apply and to consolidate the concepts learned in the classroom. As bibliographic base, this project sought references in academic books, on-line portals and articles about the use of ludic methods in education and the learning through the computers games.
\end{abstract}

Keywords: Chemical Risk; Learning; Biosafety; Digital Game; Education.

\section{Introdução}

O ensino convencional tem passado por grandes mudanças ao longo dos anos, pautando-se nos métodos, materiais e equipamentos inerentes a cada época. Como se intenta sempre aprimorar o processo de aprendizagem, proporcionando o desenvolvimento de novas técnicas, o ato de aprender tende a se tornar, cada vez mais, uma atividade atrativa e prazerosa. As novas gerações já nasceram sob a era digital. Por isso, os estudantes e jovens profissionais de hoje tendem a ser mais rápidos, mais dinâmicos e conhecem a tecnologia com enorme propriedade. Para despertar o interesse dos "nativos digitais" e aproveitar seu entusiasmo e capacidade de aprendizagem, o ensino deve adaptar-se aos novos tempos e buscar utilizar os recursos tecnológicos disponíveis no processo de ensino-aprendizagem (PRENSKY, 2012).

Nos dias atuais, com o alto avanço das tecnologias de informação e comunicação, as ferramentas de suporte à aprendizagem transformam as maneiras de transmissão de conhecimento e fornecem métodos que contradizem o modelo tradicional. A velocidade da informação proporciona e exi- 
ge uma aprendizagem dinâmica e, nesse modelo de ensino, os jogos digitais transitam perfeitamente, tratando o aprendizado como diversão e não como algo maçante e repetitivo, ainda que possam, algumas vezes, abordar temas complexos. Dentre as diversas áreas do conhecimento, conceitos básicos de Química, de Biologia e de disciplinas relacionadas à área da saúde passam, também, a ser utilizados em jogos digitais nos diferentes níveis de ensino.

Este projeto trata os conceitos básicos de Biossegurança, conjunto de medidas que auxiliam no reconhecimento, na identificação e na prevenção de riscos do dia a dia em atividades laboratoriais. O uso de Equipamentos de Proteção Individual (EPI) no campo laboratorial, como luvas, óculos, aventais, máscaras e botas, ajuda a prevenir acidentes. O contato direto com substâncias químicas pode trazer uma diversidade de riscos ao meio ambiente e à saúde do homem. Como forma de contenção desses riscos, é necessário ter conhecimento dos materiais manipulados e dos equipamentos de proteção, além de uma infraestrutura que consiga dar segurança adequada para as pessoas que os utilizam.

\section{Justificativa}

Ainda que um leigo não possua qualquer conhecimento específico referente ao conceito de Biossegurança, é perfeitamente possível, e de certa forma até automático, imaginar que, em um ambiente laboratorial, certas práticas, tais como higienização das mãos, o uso de avental, luvas e máscaras de proteção, devam ser adotadas visando não somente à segurança do local, mas principalmente à das pessoas ali presentes. O grande problema em Biossegurança está no comportamento dos profissionais envolvidos e não nas tecnologias existentes para eliminar ou minimizar os riscos. Segundo o consultor de Biossegurança da Organização Mundial de Saúde (OMS) Jonathan Richmond, a maior responsabilidade sobre o controle de agentes perigosos é do profissional, que entende o risco e conhece os mecanismos de controle. "Nenhum microbiologista quer levar um agente perigoso para sua casa ou espalhá-lo pela rua", justifica. Mesmo assim, os erros podem aparecer (BIOSSEGURANÇA, 2005, pp. 6-8). Contando com o auxílio e o trabalho colaborativo de profissionais tanto da área de Biossegurança como de Jogos Digitais, Chemical Risk trata justamente da familiarização do aluno com os principais conceitos de Biossegurança, considerando que em um ambiente acadêmico a reprodução de um acidente real seria inviável. Por meio das dinâmicas dos jogos digitais, é perfeitamente possível viabilizar simulações de acidentes químicos em ambientes laboratoriais, proporcionando a aplicação e a consolidação, por parte do aluno-jogador, dos conceitos aprendidos em sala de aula. Por outro lado, com as mesmas dinâmicas, consegue-se auxiliar o docente, apontando dúvidas e erros mais comuns realizados pelos estudantes.

\section{Jogos Digitais na Educação}

Com a crescente disseminação da cultura de jogos digitais pelo mundo, observa-se que cada vez mais as pessoas estão interagindo com diversos tipos de jogos, em diferentes tipos de plataformas, e passando, assim, cada vez mais tempo imersas em ambientes virtuais. Boa parte desse movimento pode ser explicado pelo desenvolvimento tecnológico ocorrido nos últimos anos, aliado à qualidade dos dispositivos utilizados para a produção do entretenimento, que os tornam mais interessantes a cada dia.

Se inicialmente se pensava nas novas tecnologias como recursos meramente facilitadores de tarefas cotidianas, atualmente observa-se também, entre outras funções, seu enorme potencial para auxiliar na estrutura de aprendizagem das pessoas. Nesse contexto, o jogo digital surge como importante meio capaz de promover, de forma lúdica, esse suporte no processo de ensino-aprendizagem, mantendo a essência pedagógica do conteúdo o qual representa. Permite, dessa maneira, que alunos-jogadores aprendam novos temas, ampliando sua visão e absorvendo novas formas de reconhecer os elementos do mundo à sua volta, principalmente no que se refere 
à resolução de problemas. Cada novo desafio do jogo pode trazer consigo não somente o exercício da lógica, mas um novo conjunto de informações sobre um determinado tema, tendo como única diferença a forma como o conhecimento é transmitido e processado.

A apresentação de conceitos utilizando personagens que desempenham papéis ativos no jogo transfere aos jogadores a sensação de ser e estar no ambiente ou na situação demonstrada no jogo, pois, ao controlar um personagem que representa na prática a sua própria perspectiva do desconhecido, o entretenimento se torna mais viável e promove uma imersão mais assertiva, resultando num aprendizado mais eficiente (ALVES, 2008, pp. 3-10).

\section{Biossegurança}

Biossegurança é o conjunto de ações voltadas para a prevenção, a minimização ou a eliminação de riscos inerentes às atividades de pesquisa, produção, ensino, desenvolvimento tecnológico e prestação de serviços, visando à saúde do homem, dos animais, à preservação do meio ambiente e à qualidade dos resultados (TEIXEIRA \& VALLE, 1996). O fundamento da Biossegurança é assegurar o avanço dos processos tecnológicos e proteger a saúde humana, animal e o meio ambiente (MINISTÉRIO DO MEIO AMBIENTE apud HIRATA \& MANCINI FILHO, 2012, p. 2).

Cumprir a legislação, ser transparente e ter ética são algumas formas de ter sucesso em um laboratório. Dessa maneira, o laboratório é capaz de proteger e identificar seus produtos e os riscos que eles oferecem, prevenindo acidentes e preparando os profissionais para que saibam como proceder em situações de risco. Falta de experiência, desequilíbrio profissional e excesso de confiança são alguns dos fatores que podem causar acidentes.

Em um laboratório de pesquisa ou ensino em qualquer área podem existir cinco grupos de risco que devem ser reconhecidos, avaliados e minimizados para um bom funcionamento do local. Os grupos de risco são: químicos, físicos, biológicos, ergonômicos e de acidentes, os quais apresentam uma ampla gama de legislações e normas. Dentre todas as características de cada grupo, o risco químico pode não apenas causar danos ao homem, como também pode ocasionar um grande impacto ao meio ambiente. Materiais químicos, quando manuseados de forma inadequada, podem ser de extremo perigo e causar vários danos ao sistema biológico de quem absorve essas substâncias. No ambiente de trabalho, perigo pode ser definido como uma situação ou ato que cause danos potenciais, tais como lesões, ferimentos e problemas de saúde. Considerando que o risco é uma consequência do perigo, quando um laboratório segue as normas de Biossegurança pode minimizar ou eliminar as chances de perigo (CARMELA et al., 2013).

Para pôr em prática a Biossegurança, é necessária a conscientização sobre a utilização de materiais ou qualquer outro dispositivo que tenha a finalidade de proteger de possíveis situações que causem danos à saúde ou coloquem em risco a segurança de um indivíduo ou grupo de pessoas durante o exercício de uma determinada atividade. Esses materiais são conhecidos como EPIs (Equipamentos de Proteção Individual) e EPGs (Equipamentos de Proteção Coletiva) (HIRATA \& MANCINI FILHO, 2012).

\section{Escopo do projeto}

Para o desenvolvimento deste projeto, o jogo contará com uma fase em um ambiente com 25 salas, dispostas de forma a gerar a sensação de um labirinto (Figura 1), no qual estarão dispostos cerca de trinta itens (EPIs), distribuídos aleatoriamente. Para auxiliar no aprendizado, perguntas serão feitas quando o jogador chegar à sala correta e haverá a verificação de que todos os itens necessários tenham sido coletados pelo jogador.

O desenvolvimento do jogo estará limitado à criação de uma única fase jogável, com todos os itens necessários para sua conclusão.

\section{Conceito do Jogo}

Chemical Risk é um jogo do gênero adventure, com momentos que exigem a capacidade de 
raciocínio rápido, lógico e estratégico para a resolução de puzzles. No aspecto narrativo, o jogo relata acontecimentos ocorridos com uma estudante (Figura 2) que está estagiando em um laboratório e cursa a disciplina de Biossegurança. Essa aluna deve aplicar os conhecimentos de manutenção, organização e prevenção de acidentes nos laboratórios utilizados em seu curso. Ao se deparar com um determinado acidente químico em um dos laboratórios, ela tem a tarefa de coletar os equipamentos de proteção individual (EPIs) necessários para conter de forma segura o acidente, evitando os riscos de contaminação do ambiente.

\section{Game Design}

O jogador deverá explorar diversas salas, buscando itens - os EPIs corretos, como luvas de borracha, máscaras de gás, óculos de proteção para solucionar o problema proposto no início da fase. Caso a busca seja bem-sucedida, a porta do laboratório se abrirá e ele poderá concluir a fase efetuando a contenção do acidente. Ao coletar cada um desses itens, o aluno-jogador também deverá responder perguntas didáticas, relacionadas a assuntos anteriormente estudados.

O tempo do jogo, enquanto a personagem principal não entra no laboratório, é cronometrado regressivamente e, ao entrar no laboratório conta-

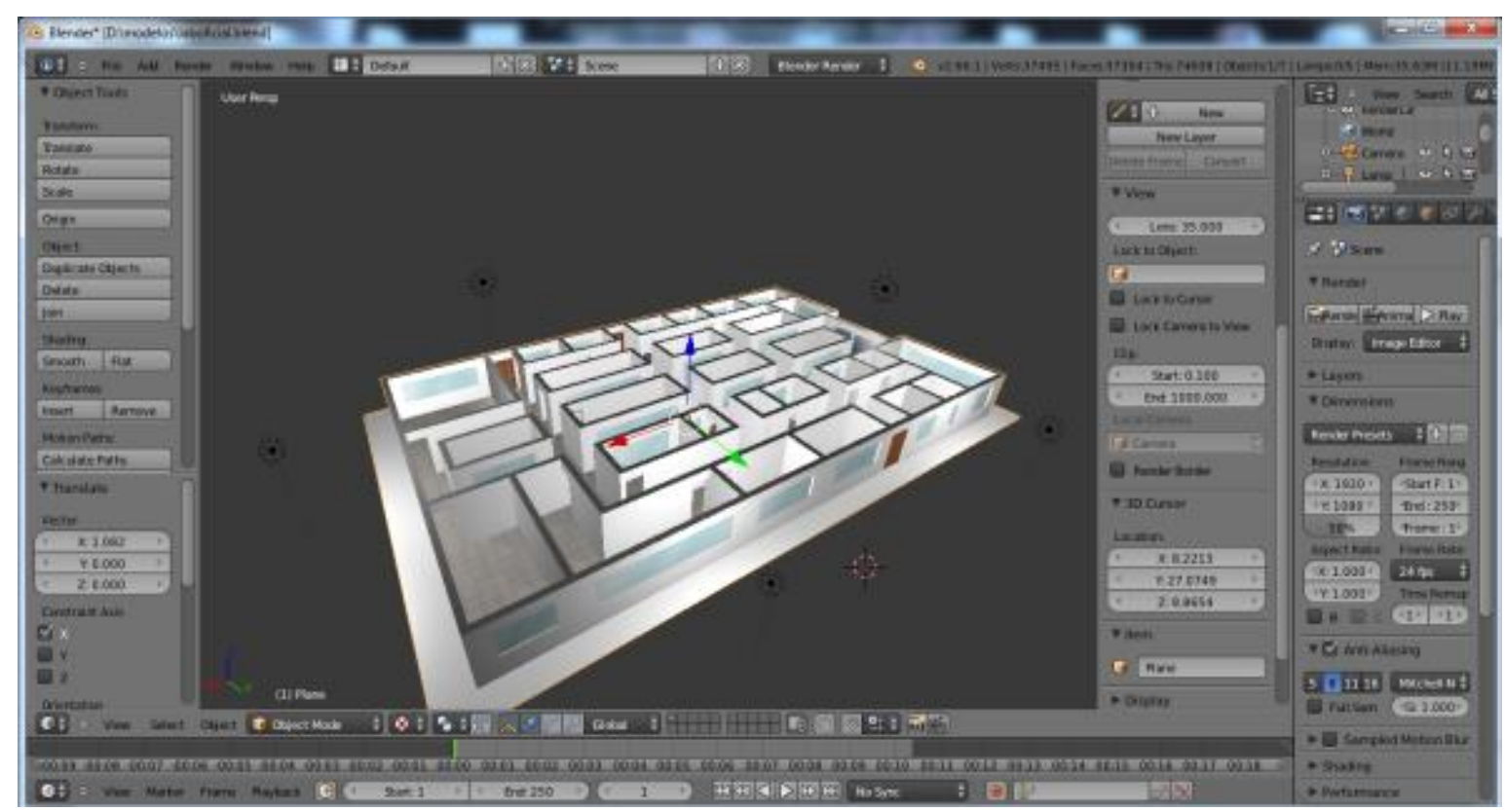

Figura 1 - Visão geral do cenário do jogo.

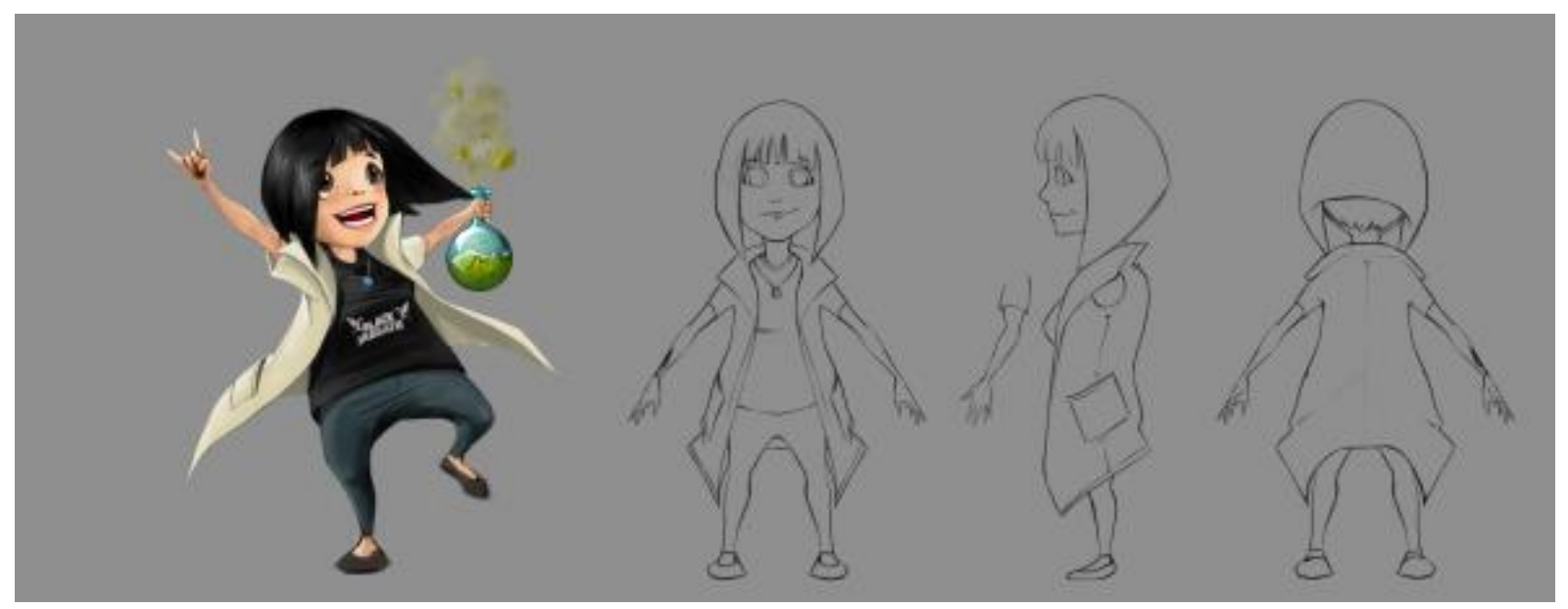

Figura 2 - Concept art da personagem do jogo. 
minado, haverá um timer, também em contagem regressiva. Quando essa contagem chega a zero, o jogo é finalizado, a contaminação não é contida e há a necessidade de reiniciar a fase para cumprir a tarefa corretamente.

O fator tempo, além de ser utilizado como base para o cálculo da pontuação do jogador ao final de cada fase, serve como elemento de punição, pois causa certa tensão no jogador. A distribuição dos itens coletáveis, assim como as perguntas que dão acesso a fases ou partes do cenário são aleatórias, fazendo com que o jogador não saiba exatamente onde tais elementos estarão cada vez que reiniciar o jogo, nem quais perguntas deverão ser respondidas.

A personagem se movimenta com o clique esquerdo do mouse. Se o jogador clicar em determinado local do mapa, ela se movimentará em linha reta até este local ou até colidir com o cenário. Se o jogador mantiver pressionado o botão esquerdo do mouse, a personagem seguirá o cursor.

\section{Instructional Quest Design}

As missões, assim como o objetivo principal do jogo, foram tratadas de modo a cumprir o propósito ludopedagógico de interação no am- biente virtual. Assim, consideramos algumas premissas importantes:

- Ao tentar abrir a porta do laboratório para concluir o objetivo proposto, é testado se o jogador já coletou todos os itens necessários. Caso não os tenha, uma mensagem aparece informando sobre a necessidade de coletá-los. Concluindo com sucesso essa etapa, é acionada a segunda validação, que surge em forma de pergunta. Caso a resposta esteja correta, é liberado o acesso à sala onde o jogador tem um tempo menor para cumprir o objetivo.

- Ao colidir com um objeto, caso o slot dele esteja disponível, esse objeto é armazenado. Caso contrário, é exibida uma mensagem perguntando se o jogador deseja substituir o objeto já coletado pelo novo. Se a resposta for sim, o objeto anterior é movido para o local onde estava o objeto agora coletado.

- Para acessar o laboratório, é feita uma pergunta didática ao jogador, e ele só consegue entrar se respondê-la corretamente. Para cada resposta incorreta é gerada uma nova pergunta.

- Para iniciar uma missão (Figura 3), o jogador precisa ler um descritivo do acidente, que deve fornecer informações suficientes para que o jogador saiba quais são os itens necessários para cumprir a tarefa com sucesso.

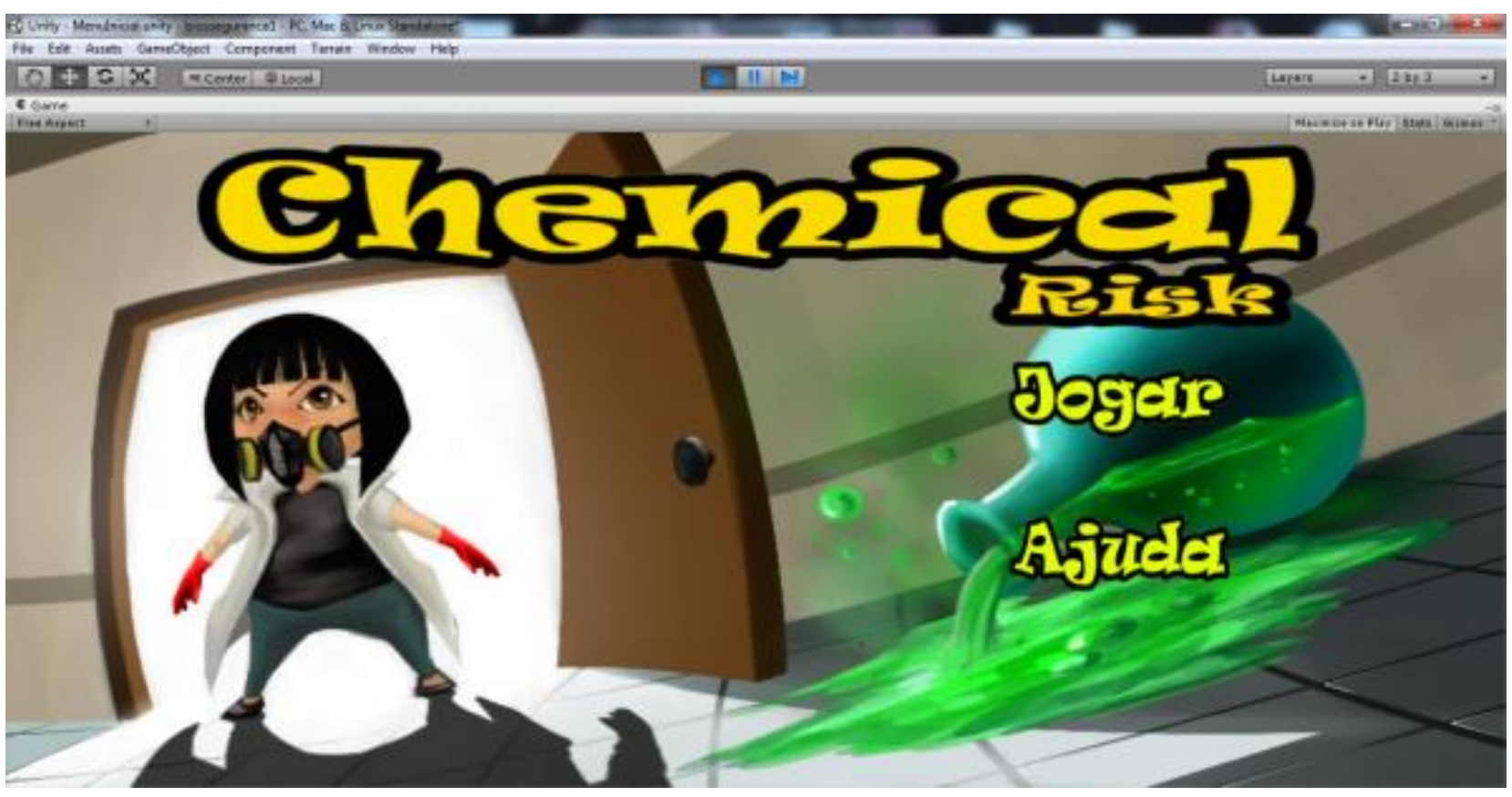

Figura 3 - Menu inicial do jogo. 


\section{Conclusão}

A educação não se restringe às salas de aula, aos livros e aos professores. Atualmente, dispõe-se de diversas plataformas para criar e compartilhar conhecimento. A partir dos jogos digitais podemos inserir, por meio do universo virtual, uma realidade para a prática de diversas ações em diversas áreas. Biossegurança é uma delas.

Este projeto apresenta aos alunos de áreas que envolvam o conceito de Biossegurança uma forma de aprender na prática, porém mediante simulações em ambiente virtual, a lidar, de forma segura, com as mais diversas situações de risco dentro de um laboratório, já que, na prática do dia a dia, tais simulações não representam a realidade de forma consistente e coesa. Mais do que simplesmente "jogar", o aluno pode exercitar e fixar todos os conceitos apresentados em aula.

Partindo do princípio de que "a prática leva à perfeição", Chemical Risk pode fazer com que o aluno treine e assimile as ações necessárias para desenvolver seu papel na sociedade de uma forma segura para si, para os envolvidos e para o meio ambiente.

\section{Referências Bibliográficas}

ALVES, L. "Relações entre os Jogos Digitais e Aprendizagem: Delineando Percurso". Educação, Formação d Tecnologias, vol. 1, n. 2, nov. 2008, pp. 3-10. Disponível em: 〈http://eft.educom.pt/index.php/eft/article/ viewFile/58/38>. Acessado em 22 abr. 2013.

BIOSSEGURANÇA. A Importância do Controle dos Riscos. Boletim Informativo da Anvisa. Brasília, ago. 2005, pp. 6-8.

CARMELA, A.; LINS, D. \& ALÉCIO, E. "Riscos Químicos + EPI + EPC". Curso Técnico em Química Industrial, Centro Federal de Educação Tecnológica de Pernambuco, s.d.

HIRATA, Mário Hiroyuki \& MANCINI FILHO, Jorge. Manual de Biossegurança. 2. ed. São Paulo: Manole, 2012.

PRENSKY, M. Aprendizagem Baseada em Fogos Digitais. São Paulo: Senac, 2012.

TEIXEIRA, P. \& VALLE, S. Biossegurança: uma Abordagem Multidisciplinar. Rio de Janeiro: Fiocruz, 1996.

Publicado em 11/11/2016. 